\title{
Unsanctioned travel restrictions related to Ebola unravel the global social contract
}

\author{
Reena Pattani MDCM
}

Competing interests: None declared.

This article has been peer reviewed.

Correspondence to: Reena Pattani, pattanir@smh.ca

CMAJ 2015. DOI:10.1503

/cmaj.141488
$\mathrm{W}$

e are currently facing the worst Ebola outbreak since the virus was isolated. On Oct. 28, 2014, Australia became the first country among high-income nations to institute a restriction on travel from the three West African countries at the centre of the outbreak: Guinea, Liberia and Sierra Leone. ${ }^{1}$ Canada followed suit on Oct. 31 by similarly refusing visas to residents of, and recent travellers to, these countries. ${ }^{2}$ Days later, the World Health Organization (WHO) demanded justification for these measures because they are not consistent with the spirit of the revised International Health Regulations of 2005. ${ }^{3}$ The disregard by Australia and Canada of the treaty harms the global social contract and our ability to respond collectively to future epidemics.

By the end of November 2014, a total of 15935 confirmed, suspected or probable cases of Ebola and 5689 deaths from the disease had been recorded. ${ }^{4}$ Guinea, Liberia and Sierra Leone have been the hardest hit, but cases have also been documented in Mali, Nigeria, Senegal, Spain and the United States, with a separate controlled outbreak in the Democratic Republic of Congo. ${ }^{4}$

The revised International Health Regulations provide a mechanism to coordinate global action during public health emergencies of this magnitude. The origins of the treaty can be traced to the International Sanitary Conferences of 1851, which yielded a set of conventions outlining policies for quarantine to halt the spread of cholera, plague and yellow fever. This collective action eventually impelled the formation, in 1948, of WHO itself. ${ }^{5}$ Among the first undertakings of the newly created WHO was the consolidation of the

\section{- KeY POINTS}

- Canada and Australia are among 30 countries to have instituted restrictions on travel from the three West African countries most affected by Ebola virus disease.

- The restrictions defy the revised International Health Regulations' emphasis on avoiding unnecessary interference with international traffic and trade during infectious disease outbreaks and are not supported by evidence.

- This disregard harms the global social contract and degrades our ability to respond appropriately to future epidemics. conventions into a single piece of legislation known as the International Sanitary Regulations. ${ }^{6}$ Over the next few decades, the regulations were renamed the International Health Regulations. Minor modifications were made to reflect the changing epidemiology of infectious diseases that posed a global threat, although the focus remained largely disease specific. ${ }^{5}$ In 1995 , the decisionmaking body of WHO convened to address limitations in the vision and scope of the regulations. A set of revisions entered into force in 2007. They required that the 196 signatories of the International Health Regulations establish minimum core capacities in health care to facilitate timely recognition and response to public health emergencies (biologic, chemical or radionuclear) that could have a global impact.

From the outset, one of the core tenets of the International Health Regulations has been an emphasis on avoiding "unnecessary interference with international traffic and trade." Practically, this means that individual nation-states are not at liberty to impose travel restrictions in the absence of a WHO recommendation or scientific evidence. Australia and Canada are among about 30 jurisdictions that have imposed some form of restriction against travellers from the countries currently experiencing the worst of the Ebola outbreaks. ${ }^{8}$ As the only two high-income countries on the list, their actions have the greatest potential to degrade the International Health Regulations and, more generally, global cooperation during infectious disease outbreaks.

The travel restrictions imposed by Australia and Canada might be justified if they were supported by expert consensus or evidence, but they are not. Researchers in Canada have recently used Ebola surveillance data coupled with international air transport data to show that only two or three travellers with Ebola might depart the affected countries per month. ${ }^{9}$ This finding supports the use of public health strategies such as airport exit screening, but it calls into question the use of specific restrictions on travel. Furthermore, of the handful of people with Ebola contracted or treated in the United States to date, all save two have been successfully managed with the supportive

All editorial matter in CMAJ represents the opinions of the authors and not necessarily those of the Canadian Medical Association. 
care resources available in North America. In one case, the outcome could have probably been prevented had a proper travel history been taken and appropriate management instituted at first presentation. In the second, the patient was transported to the United States in an already critical condition after nine days of having symptoms. Contrasted with the devastation from the disease seen in West Africa, where a case-fatality rate of $60 \%$ $70 \%$ has been observed, ${ }^{4,10}$ it becomes painfully apparent that the risk of dying from Ebola virus disease is highest where there are systemic failures such as an absent health care infrastructure, lack of necessary equipment and a shortage of trained personnel. ${ }^{11}$

The Ebola outbreak has highlighted a need to re-evaluate the purpose of international treaties and how they are put into use under WHO. Despite the substantial normative authority of WHO, the organization faces challenges in generating collective agreements between its signatories. ${ }^{12}$ Among the greatest challenges is balancing the competing goals of global cooperation and state autonomy. ${ }^{13}$ In 1994, the United Nations Development Programme drafted its annual Human Development Report and included a chapter titled "New Dimensions of Human Security"14 that explicitly linked human security and health concerns. ${ }^{15}$ Regrettably, the very concept of global health security builds a "threat protection mentality" that risks emphasizing national sovereignty over global solidarity. ${ }^{15}$ This thinking has been apparent in the discourse around the current Ebola epidemic.

The particular defiance by Australia and Canada sets an example that may prompt low-income countries to reconsider what binds them to the global community - a community that is supposed to share obligations through treaties such as the International Health Regulations. The revised regulations mandated the establishment and maintenance of an infrastructure for disease surveillance as a core capacity that countries must develop. Surveillance has the potential of serving the global community, but perhaps at the expense of lowincome countries. Low-income countries may question what they have to gain from sharing surveillance data and reporting outbreaks transparently when other signatories to the International Health Regulations are not maintaining their commitments to the same treaty..$^{15}$ The financial repercussions of sharing data obtained through surveillance, which may result in trade or travel restrictions, will disproportionately affect already vulnerable economies. ${ }^{16,17}$ Canada itself experienced such effects during the outbreak of severe acute respiratory syndrome (SARS) in 2002/03; as a result of a WHOimposed travel ban, it suffered direct and indirect losses estimated at $\$ 2$ billion. ${ }^{18}$ At that time, con- cerns were raised that earlier reporting and greater transparency about the outbreak in China might have lessened the international reach of the outbreak; however, the economic devastation that might result from trade and travel advisories, or even simply from fear and stigma, was a major disincentive to report. ${ }^{19}$ Underreporting is also a concern in the current Ebola outbreak, ${ }^{20}$ particularly in the aftermath of the travel restrictions.

Other priority capacities outlined in the International Health Regulations include enhancing public health response, preparedness, human resources and laboratory services, ${ }^{21}$ because development of these capacities in all nation-states has the greatest potential to thwart the impact of emerging infectious diseases on a global scale. ${ }^{16}$ The target for establishing these capacities was 2012 - a deadline that was missed by the global community with little attention - and required several governments to pursue extensions through WHO. ${ }^{22}$ Without the establishment of an adequate health system infrastructure in low-income nations, the global response to outbreaks will be, at best, a perpetuation of interstate reliance, ${ }^{23}$ with a focus on charity at the expense of capacity-building. Furthermore, a global response to public health emergencies, and the necessary commitment of resources, may be invoked long after a low-income country's threshold for containment, and its ability to protect its citizens, has been exceeded.

Despite coming into force in 2007, the revised International Health Regulations do not describe specific penalties for noncompliant member states. ${ }^{17}$ The mechanism for dispute settlement is rooted in negotiation and mediation. Without a means of enforcement, the consequences of noncompliance are merely a "tarnished international image, ... economic and social disruption, and public outrage." 5 Since Canada and Australia instituted unsanctioned travel restrictions, one can see that high-income countries have sufficient political capital to be noncompliant with relative impunity.

The Ebola outbreak has created an imperative to revisit the International Health Regulations and consider how they represent a global social contract. The treaty should supersede shortsighted interests of individual states. Individual nation-states must consider how their actions might contribute to the unravelling of global partnerships that were created to promote the public's health. It is clear that the Ebola outbreak is a cause for panic moral panic - over how we wish to conduct ourselves in a global community.

See references, www.cmaj.ca/lookup/suppl/doi:10.1503/cmaj .141488/-/DC1

Affiliations: Harvard School of Public Health, Boston, Mass.; Division of General Internal Medicine, St. Michael's Hospital, Toronto, Ont. 